\title{
A-priori calculation of the refractive index of some simple gas hydrates of structures I and II
}

\author{
O. Bonnefoy ${ }^{*}$, F. Gruy, J.-M. Herri ${ }^{1}$ \\ Ecole des Mines, UMR CNRS 5148 \\ 158 cours Fauriel, 42023 Saint-Etienne, France
}

\begin{abstract}
This work aims at providing theoretical values of the refractive index of some gas hydrates using up-to-date physical data. Indices of refraction have been computed with a modified Lorenz-Lorentz model for a pressure between 2 and $15 \mathrm{MPa}$, a temperature between 0 and $12{ }^{\circ} \mathrm{C}$ and wavelengths in the extended visible domain. Given the prohibitive time required to perform the calculations with the standard procedure (up to 20 min for one $P-T-\lambda$ set), we considered separately the crystalline structure and the molecules that occupy its sites. Thus, we obtain a series of tensors, characterising the sole structure, that we can easily use to get the refractive indices within less than $1 \mathrm{~s}$. In this paper, all data are given to calculate the absolute or relative refractive index of any gas hydrate, provided the host gas polarisability is known. The numerical results are in agreement with experimental data.
\end{abstract}

Key words: Clathrate gas hydrate; Index of refraction; Optical properties; Dielectric properties; Lorenz-Lorentz model; Light scattering

\section{Introduction}

Literature is abundant on gas hydrates, which give rise to a growing attention. The novice can safely refer to Sloan's book [1] for a detailed presentation of these crystals. Among the industrial contexts where they appear, we shall cite : hydrate plugs obstructing oilor gas-pipelines, energy resources in form of methane hydrates trapped in permafrost or sub-marine sediments, natural gas transport in form of a slurry or gas separation by fractionnated crystallisation.

The intelligent exploitation of hydrates in these contexts require a considerable amount of scientific data and the research efforts of many nations (United

\footnotetext{
* Corresponding author. Tel.: +33-4-7742-0272; Fax: +33 4-7749-9694

Email address: olivier.bonnefoy@emse.fr (O.

Bonnefoy).

1 www.emse.fr/fr/transfert/spin/depscientifiques/ /GENERIC/hydrates/plancentral.htm

Preprint submitted to Materials Chemistry and Physics
}

States, Russia, France, Germany, Great Britain, Japan and China, to cite the most active ones) greatly contribute to this goal. From this perspective, it seems to us that the knowledge of hydrates dielectric properties is a valuable tool, in particular for those who wish to measure the particle size distribution of hydrates in suspension via diffusion methods. Here, we need to cite the works of Melnikov et al. [2] and, previously, of Bylov and Rasmussen [3].

The structure of this document is following. We first develop the calculation method. The index of refraction is the convergence point of a macroscopic approach in terms of field and of a microscopic approach in terms of crystalline structure. We then present the experimental data we used to perform the calculations and, eventually the numerical results (absolute and relative refractive indices). Finally, we study the sensibility of the results and compare with experimental data available in the literature. 


\section{Calculation method}

We will successively use two approaches to express the polarisation $\boldsymbol{P}$ as a function of the field $\boldsymbol{E}$. The first approach is macroscopic and utilizes the dielectric permittivity $[\epsilon]$ whereas the second one is microscopic. She utilizes the crystal molecular structure and superposition principle. This method is presented in numerous reference books (see, for instance, Durand [4] or Ashcroft and Mermin [5]) and was first applied to hydrates by Herri and Gruy [6]. The comparison of the two relationships that we will get provides a mean to express the dielectric permittivity as a function of the crystal structure.

\subsection{Macroscopic approach}

When we apply an electric field $\boldsymbol{E}_{\mathrm{A}}$ to a dielectric medium, this field creates a polarisation $\boldsymbol{P}$ which, in turn, produces a depolarising field $\boldsymbol{E}_{\text {dep }}$ opposed to the applied field $\boldsymbol{E}_{\mathrm{A}}$. The total field $\boldsymbol{E}$ in the dielectric medium is the sum of the two fields :

$$
\boldsymbol{E}=\boldsymbol{E}_{\mathrm{A}}+\boldsymbol{E}_{\mathrm{dep}}
$$

The dielectric permittivity (or dielectric constant) may be defined by the following relationship between polarisation and electric field :

$$
\boldsymbol{P}=\frac{[\epsilon]-I}{4 \pi} \boldsymbol{E}
$$

\subsection{Microscopic approach}

\subsubsection{Expression of the local field}

At a given time, the macroscopic field $\boldsymbol{E}$ at position $\boldsymbol{r}$ is the spatial average of $\boldsymbol{E}_{r}^{\text {micro }}$ on a sphere of radius $r_{0}$, centered around $\boldsymbol{r}$, and such that $r_{0}$ is small compared to the macroscopic length scale and big compared to characteristic atomic dimensions (intermolecular distances). The local field $\boldsymbol{E}_{\boldsymbol{r}}^{\mathrm{loc}}$ at $\boldsymbol{r}$ is the existing field at $\boldsymbol{r}$ if we remove the atome at this place. To calculate it, we decompose the space into two zones : one sphere $B$ of radius $r_{1}$ centered at $\boldsymbol{r}$ and the rest of the space $\bar{B}$. We could have taken a cube but the subsequent calculations would have been more complicated. The radius $r_{1}$ is small compared to the crystal size and big compared to $r_{0}$. With this decomposition, we get :

$$
\boldsymbol{E}^{\mathrm{loc}}=\boldsymbol{E}_{\bar{B}}^{\mathrm{loc}}+\boldsymbol{E}_{B}^{\mathrm{loc}}
$$

Since $r_{1}$ is big compared to $r_{0}, \boldsymbol{E}_{\bar{B}}^{\text {loc }}$ may be approximated by the average of the microscopic electric field existing out of the sphere $B$, i.e., by the macroscopic field $\boldsymbol{E}_{\bar{B}}^{\text {macro }}$. Moreover, the macroscopic field $\boldsymbol{E}$ may be decomposed in :

$$
\boldsymbol{E}=\boldsymbol{E}_{B}^{\text {macro }}+\boldsymbol{E}_{\bar{B}}^{\text {macro }}
$$

where $\boldsymbol{E}_{B}^{\text {macro }}$ is the macroscopic field that would exist if there were only the charges in $B$ (included the atom at $\boldsymbol{r}$ ). Thus, Eq. (3) becomes :

$$
\boldsymbol{E}^{\mathrm{loc}}=\left(\boldsymbol{E}-\boldsymbol{E}_{B}^{\text {macro }}\right)+\boldsymbol{E}_{B}^{\text {loc }}
$$

Given the previous decomposition of the macroscopic field $\boldsymbol{E}$, we finally get :

$$
\boldsymbol{E}^{\mathrm{loc}}=\boldsymbol{E}_{\mathrm{A}}+\boldsymbol{E}_{\mathrm{dep}}-\boldsymbol{E}_{B}^{\text {macro }}+\boldsymbol{E}_{B}^{\text {loc }}
$$

\subsubsection{Geometrical simplifications}

The hydrate particle is spherical, as well as the cavity that we have diged around the point. This is for sure an advantage since the field in a uniformly polarised sphere does not depend on its diameter and equals the Lorentz field. We can deduce that :

$$
\boldsymbol{E}_{B}^{\text {macro }}=\boldsymbol{E}_{\mathrm{dep}}=\frac{-4 \pi}{3} \boldsymbol{P}
$$

Thanks to this relationship, the equation of the local field can be simplifed in :

$$
\boldsymbol{E}^{\mathrm{loc}}=\boldsymbol{E}_{\mathrm{A}}+\boldsymbol{E}_{B}^{\mathrm{loc}}
$$

\subsubsection{Calculation of the field $\boldsymbol{E}_{B}^{\mathrm{loc}}$}

The methane hydrate structure is such that water molecules are located on three types of cristallographic sites and gas molecules on two types of cristallographic sites. We now study the case where the center of the sphere $B$ is a site of type $k$. For clear understanding, we replace the notation $\boldsymbol{E}_{B}^{\text {loc }}$ by $\boldsymbol{E}_{B_{k}}^{\text {loc }}$. The field $\boldsymbol{E}_{B_{k}}^{\text {loc }}$ is the electric field created by the presence of water and gas molecules in the sphere $B$. We group together the contributions of molecules placed on a same type of site $i$.

$$
\boldsymbol{E}_{B_{k}}^{\text {loc }}=\sum_{i=1}^{5} \boldsymbol{Z}_{i}=\sum_{i=1}^{5} \sum_{j \in B} \boldsymbol{E}_{k, j(i)}
$$

where $\boldsymbol{Z}_{i}$ is the sum of the fields $\boldsymbol{E}_{k, j(i)}$ created by the molecules $j(i)$ located on a site of type $i$. The electric field created on a site $k$ by a dipole-molecule $j$ located on a site $i$ is ${ }^{2}$ :

$$
\boldsymbol{E}_{k, j(i)}=\frac{3\left(\boldsymbol{p}_{i} \boldsymbol{r}_{k j}\right) \boldsymbol{r}_{k j}-\left\|\boldsymbol{r}_{k j}\right\|^{2} \boldsymbol{p}_{i}}{\left\|\boldsymbol{r}_{k j}\right\|^{5}}
$$

with $\boldsymbol{r}_{k j}=\overrightarrow{K J}=\overrightarrow{O J}-\overrightarrow{O K}$. To go further, we express the dipole moment of a molecule $j$ located on a site of type $i$ with its total polarisability $\alpha_{i}$ and the local field

\footnotetext{
2 Rigorously, we should utilize the index $j(i)$ instead of $i$ when we write $\boldsymbol{p}_{i}$ and $\alpha_{i}$, because the dipole moment and the polarisability do not depend on the site $i$ but on the molecule $j$ that occupies it. However, in hydrate, each site is occupied by only one type of molecule and, to keep it easy to read, we will use the compact writing.
} 
$\boldsymbol{E}_{i}^{\text {loc }}$ that acts on it : $\boldsymbol{p}_{i}=\alpha_{i} . \boldsymbol{E}_{i}^{\text {loc }}$. Consequently, we get

$$
\boldsymbol{E}_{B k}^{\mathrm{loc}}=\sum_{i=1}^{5} \sum_{j \in B} \alpha_{i} \frac{3\left(\boldsymbol{E}_{i}^{\mathrm{loc}} \boldsymbol{r}_{k j}\right) \boldsymbol{r}_{k j}-\left\|\boldsymbol{r}_{k j}\right\|^{2} \boldsymbol{E}_{i}^{\mathrm{loc}}}{\left\|\boldsymbol{r}_{k j}\right\|^{5}}
$$

Coming back to Eq. (5), we have $\boldsymbol{E}_{k}^{\text {loc }}=\boldsymbol{E}_{\mathrm{A}}+\boldsymbol{E}_{B k}^{\mathrm{loc}}$. In form of matrices, we have :

$$
\boldsymbol{E}_{k}^{\mathrm{loc}}=\boldsymbol{E}_{\mathrm{A}}+\sum_{i=1}^{5} \alpha_{i}\left[W_{k i}\right] \boldsymbol{E}_{i}^{\mathrm{loc}}
$$

where

$$
W_{k, i, q, q q}=\sum_{j \in B} \frac{3 K J_{q q} K J_{q}-\|\overrightarrow{K J}\|^{2} \delta_{q, q q}}{\|\overrightarrow{K J}\|^{5}}
$$

Through Eq. (6), we see that the local field $\boldsymbol{E}_{k}^{\text {loc }}$ depends on the four other local fields $\boldsymbol{E}_{i}^{\text {loc }}$ and on $\boldsymbol{E}_{\mathrm{A}}$. We solve numerically this system of five equations and five unknowns and we obtain the five following equalities, for $k \in\{1, \ldots, 5\}$ :

$$
\boldsymbol{E}_{k}^{\text {loc }}=\left[\gamma_{k}\right] \boldsymbol{E}_{\mathrm{A}}
$$

With the assumption of linearity with respect to polarisabilities, we decompose the tensors $\left[\gamma_{k}\right]$ in a sum of terms where the crystalline structure and the polarisability of its constituting molecules are dissociated :

$$
\left[\gamma_{k}\right]=I+\sum_{i=1}^{5} \alpha_{i}\left[T_{k i}\right]
$$

\subsubsection{Calculation of the matrices $[T]$}

To calculate each of the matrices $\left[T_{k i}\right]$, we will study the five particular cases where all polarisabilities are equal to zero excepted the polarisability of the component located on sites $i: \alpha_{i}=1$. Then, we will proceed in two steps. We will first calculate the tensor $\left[T_{i i}\right]$ and second, use it to deduce the four other tensors $\left[T_{k i}\right]$ $(k \in\{1 \ldots 5\}-\{i\})$. Henceforth, we omit the exponent "loc" in the writing of the field $\boldsymbol{E}_{k}^{\text {loc }}$.

Calculation of $\left[T_{i i}\right]$. Equation (6) written for $k=i$ leads to ${ }^{3}$ :

$$
\boldsymbol{E}_{i}=\boldsymbol{E}_{\mathrm{A}}+\left[W_{i i}\right] \boldsymbol{E}_{i}
$$

In our case, Eq. (8) becomes $\left[\gamma_{k}\right]=I+\left[T_{i i}\right]$, so Eq. (7) turns into

$$
\boldsymbol{E}_{i}=\left(I+T_{i i}\right) \boldsymbol{E}_{\mathrm{A}}
$$

3 In the particular case of hydrate of structure $I$, the sites $k=4$, occupied by the gas molecules in the small cavities, form a cubic lattice. For this reason, in such site, the contribution to the local field of the molecules located on same sites is equal to zero and consequently the tensor also : $T_{44}=[0]$.
If we compare this equation with the previous one, we have :

$$
\left[T_{i i}\right]=\left[I-W_{i i}\right]^{-1}-I
$$

Calculation of $\left[T_{k i}\right]$ for $k \neq i$. Equation (6) written for $k \neq i$ leads to

$$
\begin{aligned}
\boldsymbol{E}_{k} & =\boldsymbol{E}_{\mathrm{A}}+\left[W_{k i}\right] \boldsymbol{E}_{i} \\
& =\boldsymbol{E}_{\mathrm{A}}+\left[W_{k i}\right]\left(I+T_{i i}\right) \boldsymbol{E}_{\mathrm{A}}
\end{aligned}
$$

Equations (7) and (8) give

$$
\boldsymbol{E}_{k}=\left(I+T_{k i}\right) \boldsymbol{E}_{\mathrm{A}}
$$

So, finally

$$
\left[T_{k i}\right]=\left[W_{k i}\right]\left[I-W_{i i}\right]^{-1}
$$

\subsubsection{Polarisation}

The polarisation $\boldsymbol{P}$ of the dielectric material can be calculated as a function of the dipole moments $\boldsymbol{p}_{k}$ of the molecules located on sites $k$ and their respective volume concentration $N_{k}$ :

$$
\begin{aligned}
\boldsymbol{P} & =\sum_{k=1}^{5} N_{k} \boldsymbol{p}_{k} \sum_{k=1}^{5} N_{k} \alpha_{k} \boldsymbol{E}_{k}^{\mathrm{loc}} \\
& =\sum_{k=1}^{5} N_{k} \alpha_{k}\left[\gamma_{k}\right] \boldsymbol{E}_{\mathrm{A}}=[S] \boldsymbol{E}_{\mathrm{A}}
\end{aligned}
$$

where the agregate $[S]$ is a tensor defined by

$$
[S]=\sum_{k=1}^{5} N_{k} \alpha_{k}\left[\gamma_{k}\right]
$$

Moreover, the combination of Eqs. (1) and (4) leads to

$$
\boldsymbol{E}_{\mathrm{A}}=\boldsymbol{E}+\frac{4 \pi}{3} \boldsymbol{P}
$$

From this, we extract $\boldsymbol{P}$ and express it as a function of $\boldsymbol{E}$

$$
\boldsymbol{P}=\left(I-\frac{4 \pi}{3}[S]\right)^{-1}[S] \boldsymbol{E}
$$

\subsubsection{Link between the two approaches}

Comparing Eqs. (2) and (9), we find the equality

$$
\frac{[\epsilon]-I}{4 \pi}=\left(I-\frac{4 \pi}{3}[S]\right)^{-1}[S]
$$

which leads to the final expression of the relative dielectric permittivity :

$$
\left[\epsilon_{r}\right]=I+4 \pi\left(I-\frac{4 \pi}{3}[S]\right)^{-1}[S]
$$

To sum up, we need first to calculate the matrices [ $\left.W_{k i}\right]$ and deduce from that the matrices $\left[T_{k i}\right]$. Then, we build the tensors $\left[\gamma_{k}\right]$ and the agregate $[S]$. Then it is easy to compute the dielectric permittivity tensor $\left[\epsilon_{r}\right]$ and extract from it the absolute refractive index of the hydrate. 


\subsection{Calculation of the index of refraction}

The tensor $\left[\epsilon_{r}\right]$ has three eigenvalues : $\epsilon_{1}, \epsilon_{2}$ and $\epsilon_{3}$. The main indices of refraction are then $n_{1}, n_{2}$ and $n_{3}$ so that : $n_{i}^{2}=\epsilon_{i}$ for $i \in\{1,2,3\}$. Let us consider an electric displacment in the direction of the unit vector $\boldsymbol{u}=\left(\begin{array}{l}u_{1} \\ u_{2} \\ u_{3}\end{array}\right)$. We have the equality $u_{1}^{2}+u_{2}^{2}+u_{3}^{2}=1$. Given the random crystal orientation, we have $u_{1}^{2}=$ $u_{2}^{2}=u_{3}^{2}$. The ellipsoïd of polarisability is :

$$
\frac{u_{1}^{2}}{n_{1}^{2}}+\frac{u_{2}^{2}}{n_{2}^{2}}+\frac{u_{3}^{2}}{n_{3}^{2}}=\frac{1}{n^{2}}
$$

Consequently, the index of refraction $n$ can be written

$$
n=\sqrt{\frac{3}{n_{1}^{-2}+n_{2}^{-2}+n_{3}^{-2}}}
$$

So, the relative index of refraction $m$ is equal to :

$$
m=\frac{n}{n_{\text {water }}}=\sqrt{\frac{3 n_{\text {water }}^{-2}}{n_{1}^{-2}+n_{2}^{-2}+n_{3}^{-2}}}
$$

\section{Numerical data}

As will show the sensitivity study, special emphasis must be given to the precision of experimental data involved in the calculation of the relative index of refraction of the crystal.

\subsection{Description of the crystal}

The nature and, above all, the volume of the gas molecules trapped in the hydrate determine its crystalline structure. In the pressure and temperature conditions of our good old earth, there are two cubic crystalline forms, both composed of a juxtaposition of two kinds of cavities. These rigid cages are made out of water molecules and can contain a gas molecule in a state similar to gaseous state. The description of the crystalline structure that we have used was established by Stackelberg and Müller [7]. The unit cell ${ }^{4}$ of the crystal of structure sI (group Pm3n) consists of 2 small cages $5^{12}$ and 6 big cages $5^{12} 6^{2}$, whereas the unit cell for structure sII (group Fd3m) consists of 16 small cages $5^{12}$ and 8 big cages $5^{12} 6^{4}$. In this article, we study hydrates of $\mathrm{CH}_{4}, \mathrm{C}_{2} \mathrm{H}_{6}, \mathrm{CO}_{2}, \mathrm{H}_{2} \mathrm{~S}, \mathrm{C}_{3} \mathrm{H}_{8}$ and $\mathrm{N}_{2}$. The four first gases form hydrates of structure sI and the two latter hydrates of structure sII.

\footnotetext{
$\overline{{ }^{4} \text { A cage }} a^{b}$ is a cage composed of $b$ faces with $a$ sides each
}

\subsection{Non-stoechiometry of hydrates}

If all cages were filled with a gas molecule, the structure sI hydrate formula would be $\left(\mathrm{H}_{2} \mathrm{O}\right)_{46} \cdot(\text { gas })_{8}$ and the structure sII hydrate formula would be $\left(\mathrm{H}_{2} \mathrm{O}\right)_{136} \cdot(\text { gas })_{24}$. In fact, the occupancy rate $\theta_{k}$ of a cage of type $k$ depends on pressure and temperature and is inferior to $100 \%$. Adsorption theory, developped by Langmuir, leads to

$$
\theta_{k}=\frac{C_{k} f}{1+C_{k} f}
$$

where $C_{k}$ is a constant and $f$ is the fugacity of the fluid phase in equilibrium with the hydrate.

The two Langmuir constants $C_{1}$ and $C_{2}$ are linked to the intermolecular forces in the crystalline lattice and can be calculated theoretically using Van der Waals and Platteeuw [8] model with the Kihara potential. However, given the low sensibility of the final result towards this parameter, we will use the empirical correlation proposed by Parrish and Prausnitz [9]

$$
C_{k}=\frac{A_{k}}{T} \cdot \exp \left(\frac{B_{k}}{T}\right)
$$

Table 1 gives the constants $A_{k}$ and $B_{k}$ for the different gases studied. Numerically, in the range 270-300

Table 1

Langmuir constants $[\mathrm{K}]$

\begin{tabular}{ccccc}
\hline Gas & $A_{1}$ & $B_{1}$ & $A_{2}$ & $B_{2}$ \\
\hline $\mathrm{CH}_{4}$ & $7.228 \mathrm{E}-4$ & 3187 & $2.335 \mathrm{E}-2$ & 2653 \\
$\mathrm{C}_{2} \mathrm{H}_{6}$ & N/A & N/A & N/A & N/A \\
$\mathrm{CO}_{2}$ & $2.474 . \mathrm{E}-4$ & 3410 & $4.246 \mathrm{E}-2$ & 2813 \\
$\mathrm{H}_{2} \mathrm{~S}$ & $2.5 \mathrm{E}-5$ & 4568 & $1.634 \mathrm{E}-2$ & 3737 \\
$\mathrm{C}_{3} \mathrm{H}_{8}$ & N/A & N/A & $5.455 \mathrm{E}-3$ & 4638 \\
$\mathrm{~N}_{2}$ & $1.617 \mathrm{E}-3$ & 2905 & $6.078 \mathrm{E}-3$ & 2431 \\
\hline
\end{tabular}

$\mathrm{K}$, the constants $C_{1}$ and $C_{2}$ take values between 0.05 and 70 . If the fugacity varies between 2 and $20 \mathrm{MPa}$, it means that the cages occupancy rates will be between 50 and $100 \%$. It is a very broad range that we could tighten considering the thermodynamical stability of partially filled cages, but that represents a safe basis for the sensibility analysis.

The fugacity $f$ of the fluid phase, described by a SoaveRedlich-Kwong-type equation of state, is computed with the compressibility $Z$ of the considered gas :

$$
\ln \frac{f}{P}=Z-1-\ln (Z-B)+\frac{A}{B} \ln \frac{Z}{Z+B}
$$

The compressibility $Z$ is solution of the cubic equation

$$
Z^{3}-Z^{2}+\left(A-B^{2}-B\right) Z-A B=0
$$

where $T$ is the absolute temperature and $R=8.314$ J.K ${ }^{-1} \cdot \mathrm{mol}^{-1}$ is the universal gas constant. The constants $A$ and $B$ are defined by $A=a P / R^{2} T^{2}$ and $B=$ 
$b P / R T$ where $a$ and $b$ are functions of the critical temperature $T_{c}$ and the critical pressure $P_{c}$ of the considered gas : $a=0.42748 \frac{R^{2} T_{c}^{2}}{P_{c}}\left(1+K\left(1-\sqrt{\frac{T}{T_{c}}}\right)\right)^{2}$ and $b=0.08664 \frac{R T_{c}}{P_{c}}$ with $K$ function of the acentric factor $\omega: K=0.480+1.875 \omega-0.176 \omega^{2}$. The numerical data for the gases studied in this article are given in Table 2 .

Table 2

Parameters to calculate the gas fugacity

\begin{tabular}{cccc}
\hline Gas & $P_{c}(\mathrm{MPa})$ & $T_{c}(\mathrm{~K})$ & $\omega(-)$ \\
\hline $\mathrm{CH}_{4}$ & 4.54 & 190.6 & 0.008 \\
$\mathrm{C}_{2} \mathrm{H}_{6}$ & 4.82 & 305.4 & 0.098 \\
$\mathrm{CO}_{2}$ & 7.28 & 304.2 & 0.225 \\
$\mathrm{H}_{2} \mathrm{~S}$ & 8.82 & 373.2 & 0.100 \\
$\mathrm{C}_{3} \mathrm{H}_{8}$ & 4.19 & 369.8 & 0.152 \\
$\mathrm{~N}_{2}$ & 3.35 & 126.2 & 0.040 \\
\hline
\end{tabular}

\subsection{Polarisabilities}

The most relevant experimental situation is represented by hydrates particles in liquid water. Consequently, we are dealing with three types of molecules : - The host gas trapped in the cavities. Given that all movements are authorised (with the only exception of the translation), its polarisability is taken equal to that of the free gas under atmospheric pressure and at $0{ }^{\circ} \mathrm{C}$

- The liquid water were the hydrate particles are immersed.

- The $\mathrm{H}_{2} \mathrm{O}$ molecules that consitute the cavities. Given that the hydrogen bonds that rigidify them, we consider that their volume polarisability is equal to that of the ice at hydrate pressure and temperature.

In what follows, we will study the polarisabilities for these three cases. The polarisability depends on the wavelength but also on the pressure and temperature.

\subsubsection{Gas polarisability}

The gas polarisability $\alpha$ depends on the wavelength in a complex manner. However, the range of interest is quite narrow (250-750 nm) and a polynomial interpolation is sufficient. So we take the relationship

$$
\alpha=\beta_{0}+\frac{\beta_{1}}{\lambda}+\frac{\beta_{2}}{\lambda^{2}}+\frac{\beta_{3}}{\lambda^{3}}
$$

where the constants $\beta_{i}$ depend on the considered gas, as indicated in Table 3 . The unit of the constants $\beta_{i}$ is such that, if the wavelength is expressed in $\mathrm{nm}$, then the polarisability $\alpha$ is expressed in $\AA^{3}$. Numerically, between 200 and $800 \mathrm{~nm}$, the polarisability decreases with the wavelength and ranges between 1 and $10 \AA^{3}$ for the considered gases.
Table 3

Parameters to calculate the gas polarisability

\begin{tabular}{ccccc}
\hline Gas & $\beta_{0}$ & $\beta_{1}$ & $\beta_{2}$ & $\beta_{3}$ \\
\hline $\mathrm{CH}_{4}$ & 2.511837 & $6.289468 \mathrm{E} 1$ & $-8.709333 \mathrm{E} 3$ & $4.768704 \mathrm{E} 6$ \\
$\mathrm{C}_{2} \mathrm{H}_{6}$ & 4.354728 & $1.197474 \mathrm{E} 2$ & $-1.992029 \mathrm{E} 4$ & $9.112365 \mathrm{E} 6$ \\
$\mathrm{CO}_{2}$ & 2.578497 & $4.457932 \mathrm{E} 1$ & $-3.189352 \mathrm{E} 3$ & $3.173479 \mathrm{E} 6$ \\
$\mathrm{H}_{2} \mathrm{~S}$ & 2.610619 & $1.473791 \mathrm{E} 3$ & $-6.055990 \mathrm{E} 5$ & $9.286059 \mathrm{E} 7$ \\
$\mathrm{C}_{3} \mathrm{H}_{8}$ & 6.234656 & $1.648687 \mathrm{E} 2$ & $-2.759611 \mathrm{E} 4$ & $1.354185 \mathrm{E} 7$ \\
$\mathrm{~N}_{2}$ & 1.673443 & $7.525817 \mathrm{E} 1$ & $-1.750347 \mathrm{E} 4$ & $3.387202 \mathrm{E} 6$ \\
\hline
\end{tabular}

These data come from Landolt-Börnstein's data tables [10], where we find, as a function of the wavelength $\lambda$, the index of refraction $n$ of the pure gas. The polarisability $\alpha$ is then deduced with the Lorenz-Lorentz formula :

$$
\frac{n^{2}-1}{n^{2}+2}=\frac{4 \pi \alpha N}{3}
$$

where $N$, the number of molecules per unit of volume, is

$$
N=N_{\mathrm{A}} \frac{n}{V}=N_{\mathrm{A}} \frac{P}{R T}
$$

where $P$ is the pressure and $N_{\mathrm{A}}=6.023 \times 10^{23} \mathrm{~mol}^{-1}$ the constant of Avogadro. This formula is valid if we consider that the perfect gas law correctly describes the gas behaviour in the $(P, T)$ conditions, where indices are experimentally measured. We consider it is true since the pressure is $1 \mathrm{~atm}$ and the temperature is $0{ }^{\circ} \mathrm{C}$. In this case, the numerical value of $N$ does not depend on the gas and we have $N=2.687 \times 10^{25}$. The relative deviation between the polarisability value interpolated by the polynom and the value deduced from the experimental values of the index of refraction is below $0.3 \%$, with the exception of $\mathrm{H}_{2} \mathrm{~S}$ where it is $2.4 \%$.

\subsubsection{Solid water polarisability}

The polarisability of the water molecules that consitute the hydrate cages is approximated by the polarisability of water molecules in ice. To justify this assumption, we use the fact that the hydrate crystalline structure is very close from the ice structure and that water is the main component of those two crystals. We use data given by Herri and Gruy [6] :

$$
\alpha=a+\frac{b}{\lambda^{2}}+\frac{c}{\lambda^{3}}
$$

where $\lambda$ is expressed in nm and $\alpha$ in $10^{-30} \mathrm{~m}^{3}$.

Table 4

Parameters to calculate the solid water polarisability

\begin{tabular}{ccc}
\hline $\mathrm{a}$ & $\mathrm{b}$ & $\mathrm{c}$ \\
\hline 1.4447 & 17953 & -1609200 \\
\hline
\end{tabular}




\subsubsection{Polarisability of liquid water}

A great precision is required in the calculation of the liquid water refractive index since the relative hydrate index of refraction is very sensitive to this latter. Here, we use data from the International Association for the Properties of Water and Steam [11] which very precisely evaluate the density and refractive index as a function of pressure, temperature and wavelength

$$
\begin{aligned}
\frac{n^{2}-1}{n^{2}+2} \cdot \frac{1}{\bar{\rho}} & =a_{0}+a_{1} \bar{\rho}+a_{2} \bar{T}+a_{3} \bar{\lambda}^{2} \bar{T} \\
& +\frac{a_{4}}{\bar{\lambda}^{2}}+\frac{a_{5}}{\bar{\lambda}^{2}-\bar{\lambda}_{\mathrm{UV}}^{2}} \\
& +\frac{a_{6}}{\bar{\lambda}^{2}-\bar{\lambda}_{\mathrm{IR}}^{2}}+a_{7} \bar{\rho}^{2}
\end{aligned}
$$

where $\bar{T}=T / T^{*}, \bar{\rho}=\rho / \rho^{*}$ and $\bar{\lambda}=\lambda / \lambda^{*}$. Numerical values for the coefficients are given in Table 5 . Besides, we have $T^{*}=273.15 \mathrm{~K}, \rho^{*}=1000 \mathrm{~kg} \cdot \mathrm{m}^{-3}$ and $\lambda^{*}=0.589$ $\mu \mathrm{m}$.

Table 5

Parameters to calculate the liquid water index of refraction

$$
\begin{array}{ll}
a_{0}=0.244257733 & a_{4}=1.58920570 \mathrm{E}-3 \\
a_{1}=9.74634476 \mathrm{E}-3 & a_{5}=2.45934259 \mathrm{E}-3 \\
a_{2}=-3.73234996 \mathrm{E}-3 & a_{6}=0.900704920 \\
a_{3}=2.68678472 \mathrm{E}-4 & a_{7}=-1.66626219 \mathrm{E}-2 \\
\bar{\lambda}_{\mathrm{UV}}=0.2292020 & \bar{\lambda}_{\mathrm{IR}}=5.432937
\end{array}
$$

\section{Results}

The calculation method explained above has been encoded in Matlab ${ }^{5}$ and provides the structure matrices $T_{k i}$. Then we apply these results to methane hydrate and a value of 1.346 is found for a pressure of 11 $\mathrm{MPa}$, a temperature of $1{ }^{\circ} \mathrm{C}$ and a wavelength of 750 $\mathrm{nm}$. This result is in full agreement with experimental results of Bylov and Rasmussen [3]. The appendix contains the coefficients of the $T_{k i}$ matrices for hydrates of structures sI and sII. Table 6 shows the quantity $m-1$ for methane hydrate (of structure sI) and a wavelength of $350 \mathrm{~nm}$. It is a function of the pressure and the temperature and it is a key data for light scattering measurements. In Table 7 , we can read the quantity $m-1$ for methane hydrate for different pressures and wavelengths. The temperature is set to $1^{\circ} \mathrm{C}$. Table 8 shows the influence of the gas. We can see that for $\mathrm{N}_{2}$, the

\begin{tabular}{|c|c|c|c|c|c|c|}
\hline $\mathrm{P} / \mathrm{T}$ & 0 & 3 & 6 & 9 & 12 & 15 \\
\hline 30 & 1.0034 & 0.9680 & 0.9330 & 0.8979 & 0.8625 & 0.8264 \\
\hline 50 & 1.0876 & 1.0659 & 1.0455 & 1.0260 & 1.0071 & 0.9882 \\
\hline 70 & 1.1104 & 1.0955 & 1.0823 & 1.0705 & 1.0597 & 1.0495 \\
\hline 90 & 1.1121 & 1.1013 & 1.0925 & 1.0854 & 1.0795 & 1.0747 \\
\hline 110 & 1.104 & 09 & 1.090 & 1.08 & 1.08 & 1.0829 \\
\hline 130 & 1.0910 & 1.0852 & 1.0818 & 1.0803 & 1.0804 & 1.0819 \\
\hline
\end{tabular}
hydrate index of refraction is lower than the liquid water refractive index. In comparison, $\mathrm{H}_{2} \mathrm{~S}$ hydrates are easier to detect via light scattering than $\mathrm{CH}_{4}$ hydrates.

$\overline{5}$ Available on simple request to olivier.bonnefoy@emse.fr
Table 6

$100 *(m-1)$ values for $\mathrm{CH}_{4}$ hydrate at $\lambda=350 \mathrm{~nm}$. Pressure is in bar and temperature in ${ }^{\circ} \mathrm{C}$

Table 7

$100 *(m-1)$ values for $\mathrm{CH}_{4}$ hydrate at $1^{\circ} \mathrm{C}$. Pressure is in bar and wavelength in $\mathrm{nm}$

\begin{tabular}{cccccc}
\hline $\mathrm{P} / \lambda$ & 350 & 450 & 550 & 650 & 750 \\
\hline 30 & 0.9915 & 0.9881 & 0.9539 & 0.9358 & 0.9380 \\
50 & 1.0802 & 1.0745 & 1.0393 & 1.0205 & 1.0223 \\
70 & 1.1052 & 1.0990 & 1.0635 & 1.0446 & 1.0463 \\
90 & 1.1082 & 1.1020 & 1.0665 & 1.0476 & 1.0493 \\
110 & 1.1012 & 1.0952 & 1.0598 & 1.0410 & 1.0428 \\
130 & 1.0888 & 1.0832 & 1.0480 & 1.0293 & 1.0312 \\
\hline
\end{tabular}

Table 8

$100 *(m-1)$ values for different gas hydrates $\left(\right.$ at $1^{\circ} \mathrm{C}$ and $350 \mathrm{~nm})$

\begin{tabular}{rcccc}
\hline $\mathrm{P} /$ gas & $\mathrm{CH}_{4}$ & $\mathrm{CO}_{2}$ & $\mathrm{H}_{2} \mathrm{~S}$ & $\mathrm{~N}_{2}$ \\
\hline 30 & 0.9915 & 1.0533 & 4.6008 & -0.8941 \\
50 & 1.0802 & 1.0673 & 4.5803 & -0.6796 \\
70 & 1.1052 & 1.0527 & 4.5598 & -0.5924 \\
90 & 1.1082 & 1.0377 & 4.5391 & -0.5522 \\
110 & 1.1012 & 1.0221 & 4.5184 & -0.5343 \\
130 & 1.0888 & 1.0062 & 4.4976 & -0.5289 \\
\hline
\end{tabular}

\section{Sensitivity analysis}

A study of sensitivity makes it possible to better appreciate the result precision. The relative index of refraction $h=m-1$ and the absolute index of refraction $n$ depend on the parameters $G$, which are affected by an imprecision $\Delta G$ and each contribute to the imprecision $\Delta h$ and $\Delta n$ of the final results. Table 9 shows the relative influence of the differents parameters through the sensitivity coefficient $\sigma$ defined by the relationships

$$
\begin{aligned}
& \frac{|\Delta h|}{h}=\sigma_{h} \frac{|\Delta G|}{G} \\
& \frac{|\Delta n|}{n}=\sigma_{n} \frac{|\Delta G|}{G}
\end{aligned}
$$

Numerical values are calculated with methane as host gas and for variations around the point $(P=11 \mathrm{MPa}$, 
$\left.T=1{ }^{\circ} \mathrm{C}, \lambda=750 \mathrm{~nm}\right)$.

Table 9

Influence of parameters' imprecision to the final result's imprecision

\begin{tabular}{lcc}
\hline Parameter & $\sigma_{n}$ & $\sigma_{h}$ \\
\hline Pressure & 0.0007 & 0.0575 \\
Temperature & 0.0116 & 0.6233 \\
Wavelength & 0.0100 & 0.0863 \\
Water polarisability in hydrate & 0.2204 & 21.36 \\
Gas polarisability & 0.0656 & 6.358 \\
Cage 1 occupancy rate & 0.0160 & 1.554 \\
Cage 2 occupancy rate & 0.0496 & 4.795 \\
Liquid water index of refraction & 0 & 95.93 \\
Gas fugacity & 0.0010 & 0.0959 \\
Langmuir constant $A_{1}$ & 0.0006 & 0.0575 \\
Langmuir constant $B_{1}$ & 0.0066 & 0.6425 \\
Langmuir constant $A_{2}$ & 0.0004 & 0.0384 \\
Langmuir constant $B_{2}$ & 0.0038 & 0.3740 \\
\hline
\end{tabular}

Comments. Concerning the absolute index of refraction, the most important parameters are the polarisabilities of the water consituting the hydrate cages and of the gas as well as the occupancy rate of the cavities. Concerning the relative index of refraction (with liquid water as reference), the most important parameter is by far the liquid water index of refraction. An error of $1 \%$ in its estimation leads to an error of $95 \%$ on $m-1$ ! This is a justification a posteriori of the special emphasis that we have brought to use precise experimental data. Then, the four same parameters come in order.

\section{References}

[1] E.D. Sloan, Clathrate Hydrates of Natural Gases, $2^{\text {nd }}$ ed., Marcel Dekker, New York, 1997.

[2] V.P. Melnikov, A.N. Nesterov and V.V. Feklistov, Proc. 4th Int. Conf. on Gas Hydrates, Keio University, Yokohama (2002) 706.

[3] M. Bylov and P. Rasmussen, Chem. Eng. Sci., 52 (1997) 3295.

[4] E. Durand, Electrostatique et Magnétostatique, Ed. Masson and Cie, Paris, 1953.

[5] N.W. Ashcroft and N.D. Mermin, Solid State Physics, International Edition, Saunders Company, Philadelphia, 1976.

[6] J.-M. Herri and F. Gruy, Mater. Chem. Phys., 42 (1995) 51.

[7] M. von Stackelberg and H.R. Müller, Z. für Elektrochem., 58 (1954) 25.

[8] J.H. Van der Waals and J.C. Platteeuw, Adv. Chem. Phys., 2 (1959) 1.

[9] W.R. Parrish and J.M. Prausnitz, Ind. Eng. Chem. Proc. Des. Dev., 11 (1972) 26.

[10] Landolt-Börnstein, Zahlenwerte und Funktionen aus Physik, Chemie, Astronomie, Geophysik und Technik, Vol. 2, Part 8, Springer Verlag, $6^{\text {th }}$ ed., Berlin, 1962.

[11] International Association for the Properties of Water and Steam, Release on the Refractive index of Ordinary Water Substance as a Function of Wavelength, Temperature and Pressure, www.iapws.org (1997). 


\section{Appendix A : $T_{k i}$ matrices for structure sI hydrates}

\begin{tabular}{|c|c|c|c|c|c|c|c|c|c|c|}
\hline & $d$ & 1 & 1 & 1 & 2 & 2 & 2 & 3 & 3 & 3 \\
\hline & & 1 & 2 & 3 & 1 & 2 & 3 & 1 & 2 & 3 \\
\hline & & & & 8 & 2 & 2 & 3 & - & -03 & 7 \\
\hline & 2 & & 3 & & & & & & & \\
\hline & 3 & 2 & - & & & 2 & 4 & & 2 & \\
\hline & 4 & - & 9 & 5 & 8 & 2 & 2 & - & $61:$ & .03 \\
\hline & 5 & $212 \mathrm{E}-02$ & $8.6561 \mathrm{E}-18$ & $1.1760 \mathrm{E}-17$ & $8.6701 \mathrm{E}-18$ & $-9.4493 \mathrm{E}-03$ & $-1.9796 \mathrm{E}-02$ & $1.0561 \mathrm{~F}$ & 0.00 & $-6.2718 \mathrm{E}-04$ \\
\hline & & 461 & - & 2 & - & 4 & 2 & 2 & ( 400 & \\
\hline 2 & 2 & $0125 \mathrm{E}-02$ & $7.4088 \mathrm{E}-02$ & $7.4088 \mathrm{E}-02$ & $7.4088 \mathrm{E}-02$ & $1.0125 \mathrm{E}-02$ & $7.4088 \mathrm{E}-02$ & $7.4088 \mathrm{E}-02$ & $7.4088 \mathrm{E}-02$ & 2 \\
\hline 2 & 3 & .384 & -1 & $88 \mathrm{~F}_{-}$ & $-1.40^{\circ}$ & $2-1.4396 \mathrm{E}$ & $-1.3888 \mathrm{E}-02$ & $-1.4075 \mathrm{E}$ & $2-1.3888 \mathrm{E}-02$ & 18 \\
\hline & 4 & 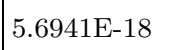 & & & & & & & & \\
\hline & & . & -1 & $-1.3888 \mathrm{E}-02$ & (5) & 8 & 2 & 2 & & \\
\hline 3 & 1 & $5784 \mathrm{E}-03$ & $2.2967 \mathrm{E}-17$ & $1.6212 \mathrm{E}-16$ & 270 & 3 & 55 & 51. & -1.9676 & \\
\hline 3 & 2 & $.4664 \mathrm{E}-02$ & $-4.7428 \mathrm{E}-03$ & $-4.7428 \mathrm{E}-03$ & $2.3714 \mathrm{E}-03$ & $3.2332 \mathrm{E}-02$ & $2.3714 \mathrm{E}-03$ & $2.3714 \mathrm{E}-03$ & $2.3714 \mathrm{E}-03$ & 3.233 \\
\hline 3 & 3 & $.9768 \mathrm{E}-03$ & $3.1481 \mathrm{E}-18$ & $-7.6790 \mathrm{E}-20$ & $3.1464 \mathrm{E}-18$ & $-4.4356 \mathrm{E}-03$ & $-1.2430 \mathrm{E}-18$ & $2.5558 \mathrm{E}-19$ & $-1.1225 \mathrm{E}$ & 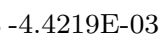 \\
\hline 3 & & 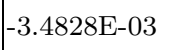 & 5 & 4 & - & 1 & 1 & 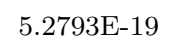 & $12825 \mathrm{~F} 11$ & \\
\hline 3 & 5 & -02 & 3 & - & -5 & is & 3 & $1-5$ & 9.435 & \\
\hline 4 & 1 & $-1.0917 \mathrm{E}-16$ & $-9.7105 \mathrm{E}-18$ & $1.4693 \mathrm{E}-18$ & $-1.9543 \mathrm{E}$ & $-9.7689 \mathrm{E}-17$ & $-1.1867 \mathrm{E}-17$ & $7-2.0952 \mathrm{E}$ & -1.464 & \\
\hline 4 & 2 & $3.2370 \mathrm{E}-16$ & $2.5335 \mathrm{E}-17$ & $2.8555 \mathrm{E}-17$ & $1.4701 \mathrm{E}-17$ & $8.5920 \mathrm{E}-17$ & $6.7482 \mathrm{E}-18$ & $6.6116 \mathrm{E}-18$ & $1.7554 \mathrm{E}-18$ & 2.1345 \\
\hline & 3 & 0786E-17 & 1.0 & 2 & -9.401 & $2.4994 \mathrm{~F}$ & $1.2881 \mathrm{E}-18$ & $9.2301 \mathrm{E}-20$ & $4.0266 \mathrm{E}-19$ & \\
\hline & 1 & 0 & 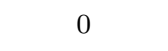 & 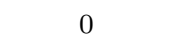 & 0 & 0 & 0 & & & \\
\hline 4 & 5 & $.0133 \mathrm{E}$ & $874 \mathrm{E}$ & $5502 \mathrm{E}-$ & $7392 \mathrm{E}$ & $.2754 \mathrm{E}-17$ & $1.0457 \mathrm{E}$ & - & 9 & 17 \\
\hline 5 & 1 & 3.3913E-02 & $-2.2141 \mathrm{E}-$ & $.3825 \mathrm{E}-$ & $2866 \mathrm{E}$ & $1.7457 \mathrm{E}-02-$ & -8.8047 & $5-$ & $7-8.8047 \mathrm{E}-05$ & \\
\hline 5 & 20 & $-6.4664 \mathrm{E}-02$ & $-4.7428 \mathrm{E}-\mathrm{C}$ & $7428 \mathrm{E}-$ & $22714 \mathrm{~F}$ & קי & $2.3714 \mathrm{E}$ & $2.3714 \mathrm{~F}$ & $2.3714 \mathrm{E}-03$ & $3.2332 \mathrm{E}-02$ \\
\hline 5 & 3 & $.3600 \mathrm{E}-02$ & $-5.0358 \mathrm{E}-1$ & $4.3593 \mathrm{E}-18$ & $-2.8644 \mathrm{E}-$ & $3-1.1643 \mathrm{E}-02$ & $-7.4700 \mathrm{E}-19$ & $1.1328 \mathrm{E}-$ & $-7.1425 \mathrm{E}$ & 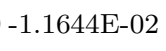 \\
\hline 5 & 4 & $-3.4828 \mathrm{E}-03$ & $5.0294 \mathrm{E}-19$ & $-9.2804 \mathrm{E}-20$ & $4.0748 \mathrm{E}-19$ & $1.7414 \mathrm{E}-03$ & $-6.2816 \mathrm{E}-20$ & $1.0442 \mathrm{E}-19$ & $-5.1005 \mathrm{E}-20$ & $1.7414 \mathrm{E}-03$ \\
\hline 5 & 5 & $.9768 \mathrm{E}-03$ & $4.6406 \mathrm{E}-18$ & $-3.5565 \mathrm{E}-19$ & $5.1294 \mathrm{E}-18$ & $-4.4219 \mathrm{E}-03$ & $8.8530 \mathrm{E}-19$ & $-3.0843 \mathrm{E}-20$ & $1.6593 \mathrm{E}-18$ & $-4.4356 \mathrm{E}-03$ \\
\hline
\end{tabular}




\section{Appendix B : $T_{k i}$ matrices for structure sII hydrates}

\begin{tabular}{|c|c|c|c|c|c|c|c|c|c|}
\hline$d$ & 1 & 1 & 1 & 2 & 2 & 2 & 3 & 3 & 3 \\
\hline$k i / e$ & 1 & 2 & 3 & 1 & 2 & 3 & 1 & 2 & 3 \\
\hline 11 & 0 & - & 4 & - & 0 & 9 & 3 & 19 & 9 \\
\hline 12 & $.0009 \mathrm{E}-10$ & $-1.1952 \mathrm{E}-$ & $7.3669 \mathrm{E}-18$ & $-1.1358 \mathrm{E}-17$ & $-1.0993 \mathrm{E}-17$ & $3.7008 \mathrm{E}-18$ & $7.8279 \mathrm{E}-18$ & $2.5619 \mathrm{E}-18$ & $-5.0920 \mathrm{E}-17$ \\
\hline 13 & $.8597 \mathrm{E}-03$ & E-02 & 2.020 & $2.2502 \mathrm{E}$ & 491E-03 & -02 & E-02 & $\mathrm{E}-02$ & 1. \\
\hline 14 & $-3.6282 \mathrm{E}-17$ & 2 . & -3 & 3 & 5.0601 & 8 & E-18 & $4.7430 \mathrm{E}-18$ & $7.9897 \mathrm{E}-17$ \\
\hline 15 & $.2868 \mathrm{E}-17$ & $2.1252 \mathrm{E}-18$ & $3.4819 \mathrm{E}-18$ & $2.1252 \mathrm{E}-18$ & $3.4293 \mathrm{E}-18$ & $7.2305 \mathrm{E}-18$ & $3.4879 \mathrm{E}-18$ & $7.3118 \mathrm{E}-18$ & $7.2277 \mathrm{E}-18$ \\
\hline 1 & $3976 \mathrm{E}-20$ & $0 \mathrm{E}-02$ & E-02 & $4.3290 \mathrm{E}-02$ & $2803 \mathrm{E}-17$ & 2 & $\mathrm{E}-02$ & $4.3290 \mathrm{E}-02$ & 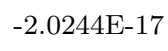 \\
\hline 22 & 3987E-05 & $6.5015 \mathrm{E}-03$ & $6.5015 \mathrm{E}-03$ & $6.5015 \mathrm{E}-03$ & 8.3987E-05 & $6.5015 \mathrm{E}-03$ & $6.5015 \mathrm{E}-03$ & $6.5015 \mathrm{E}-03$ & $8.3987 \mathrm{E}-05$ \\
\hline 23 & 9427 & $-1.1563 \mathrm{E}$ & -7.049 & $-7.5874 \mathrm{E}-02$ & $9.4369 \mathrm{E}-03$ & -7 & $-6.4933 \mathrm{E}-02$ & $-1.0447 \mathrm{E}-01$ & $-8.1100 \mathrm{E}-04$ \\
\hline 24 & $-2.7050 \mathrm{E}-\mathrm{C}$ & 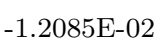 & & & 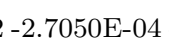 & 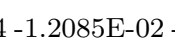 & - & - & $-2.7050 \mathrm{E}-04$ \\
\hline 5 & $5861 \mathrm{E}-18$ & $55 \mathrm{E}-03$ & 7.575 & $7.5755 \mathrm{E}-03$ & 2.3550 & $7.5755 \mathrm{E}-03$ & $7.5755 \mathrm{E}-03$ & $7.5755 \mathrm{E}-03$ & 6.727 \\
\hline 31 & $-6.3562 \mathrm{E}-03$ & 67E-03 & $7.6021 \mathrm{E}-03$ & $-7.6267 \mathrm{E}-03$ & $-6.3562 \mathrm{E}-03$ & $21 \mathrm{E}-03$ & 7.6021E-03 & $7.6021 \mathrm{E}-03$ & 1.271 \\
\hline 32 & $-3.6267 \mathrm{E}-02$ & $-1.3966 \mathrm{E}-$ & $-2.2217 \mathrm{E}-02$ & $-1.3966 \mathrm{E}-02$ & $-3.6267 \mathrm{E}-02$ & $2.2217 \mathrm{E}-02$ & $-2.1569 \mathrm{E}-02$ & $-2.1569 \mathrm{E}-02$ & $7.1789 \mathrm{E}-02$ \\
\hline 33 & $-8.9956 \mathrm{E}-02$ & -1.1 & $7.8797 \mathrm{E}-$ & -1.1686 & $3.9605 \mathrm{E}-01$ & $2.8253 \mathrm{E}-03$ & 7.8797E-03 & $2.8253 \mathrm{E}$ & -1.4156 \\
\hline 34 & 2.26 & -2 . & 1 & 2 & 3 & 1 & 1.36 & 12 & 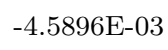 \\
\hline 35 & -2.7524 & & -5 & 1 & 3 & & & & 3 \\
\hline 41 & $-2.0600 \mathrm{E}-17$ & $3.8033 \mathrm{E}-02$ & 3.8033E-02 & 3.8033E-02 & $4.9741 \mathrm{E}-18$ & $3.8033 \mathrm{E}-02$ & $3.8033 \mathrm{E}-02$ & $3.8033 \mathrm{E}-02$ & $1.1109 \mathrm{E}-17$ \\
\hline 42 & $4.7490 \mathrm{E}-04$ & $3.6763 \mathrm{E}-02$ & $3.6763 \mathrm{E}-02$ & $3.6763 \mathrm{E}-02$ & $4.7490 \mathrm{E}-04$ & 3.6763E-02 & $3.6763 \mathrm{E}-02$ & $3.6763 \mathrm{E}-02$ & $4.7490 \mathrm{E}$ \\
\hline 43 & $4.5675 \mathrm{E}-03$ & $-6.7864 \mathrm{E}-02$ & $-4.2744 \mathrm{E}-02$ & $-4.4430 \mathrm{E}-02$ & $3.5360 \mathrm{~F}$ & $-4.2923 \mathrm{E}$ & $-3.9353 \mathrm{E}-$ & $-6.3370 \mathrm{E}-02$ & $1.3769 \mathrm{E}-03$ \\
\hline 44 & 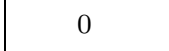 & 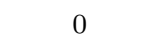 & 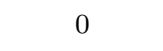 & 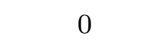 & 0 & & & 0 & 0 \\
\hline 45 & $3690 \mathrm{~F}$ & -5 & $2048 \mathrm{E}$ & -5 & 08 & $7-$ & $48 \mathrm{E}$ & -5.204 & $3-7.5$ \\
\hline 51 & $-1.3351 \mathrm{E}-1$ & 1.6 & $3218 \mathrm{E}-18$ & $6.5306 \mathrm{E}-1$ & $4.8234 \mathrm{E}$ & $3.6781 \mathrm{E}-18$ & $1.3325 \mathrm{E}-18$ & $3.6375 \mathrm{E}-18$ & $7.1064 \mathrm{I}$ \\
\hline 52 & ل & 1 & 1 & $12001 \mathrm{~F} 00$ & 20010F 10 & (or & $-1.3091 \mathrm{E}$ & (1) 120015 & م 1 \\
\hline 53 & 8.5201E-06 & $-2.5429 \mathrm{E}-$ & סק ח-תמת & $-1.7094 \mathrm{E}-$ & $5.7551 \mathrm{E}-03$ & $-9.0261 \mathrm{E}-$ & $-1.5962 \mathrm{E}$ & $600-9$ & - \\
\hline 54 & $-6.1709 \mathrm{E}-17$ & $-6.8874 \mathrm{E}-$ & $.0187 \mathrm{E}-20$ & $-7.0446 \mathrm{E}$ & $-5.6080 \mathrm{E}-17$ & $7-1.8899 \mathrm{E}-18$ & $5.4335 \mathrm{E}-19$ & $-1.1463 \mathrm{E}$ & - $-1.8799 \mathrm{E}-17$ \\
\hline 55 & 0 & $-4.7080 \mathrm{E}-$ & $-1.0579 \mathrm{E}-18$ & $-4.7351 \mathrm{E}-18$ & 3 & $-1.1591 \mathrm{E}-18$ & $-1.4916 \mathrm{E}-18$ & $-1.2680 \mathrm{E}-18$ & 0 \\
\hline
\end{tabular}

